\title{
Life Expectancy and its Regional Inequalities in Hungary
}

\author{
Annamária Uzzoli*, Dániel Szilágyi ${ }^{\mathrm{B}}$ \\ Received: July 2009 | Revised: October 2009 | Accepted: December 2009
}

\begin{abstract}
The aim of this study is to analyse the changes and the regional differences of the Hungarian life chances with the indicators of average life expectancy and mortality rate. The spatial dimension of the Hungarian health inequalities was one of our priorities, which could help us to define the typical spatial structure of health status in Hungary. We can say, the socio-economic status of Hungarian regions can determine the advantageous and the disadvantageous counties by the life chances. On the other hand, the 'Western-Eastern gradient' of the Hungarian economic environment is not very relevant in the health indicators. In the Eastern part of Hungary there are better values of GDP, for example in the cities, where the health is more advantageous. But in the Western part of Hungary, for example in South Transdanubia can be experienced one of the worst economic and health indicators in the country. The regional differentiation of the Hungarian life chances were studied with the knowledge and methodology of Health Geography and Regional Science Studies.
\end{abstract}

Key words: health inequalities, life expectancy, regional analysis methods, Health Geography

\section{Introduction}

The marked deterioration in the health status of the Hungarian population has been going on since the middle of the 1960 . As the consequence of this process Hungary is lagging behind the countries with more developed health culture. The general state of health of the Hungarian people is worse than justified by the level of economic development. The mortality rate of the relatively younger generations has been rising for years and the rate of premature mortality in the age group 40-64 is extremely high. The mortality rate of the middle-aged male population stands out by global standards. Besides, Hungary is still one of the countries in leading position in suicides and people with addictions deleterious to health represent a marked rate in the population. The mortality rate caused by malignant tumour is the highest in Hungary among the European countries. „The mortality situation in Hungary, which had been worsening for decades, developed into an epidemiological crisis by the early 1990s, and it presently hits the whole adult population" (Józan, 1991). On the other hand, the negative natural population growth rate, the very low birth rate and the ageing population has also turned to a demographic crisis in Hungary at the beginning of the 1990s (Hablicsek, 2000). Hungary's economy has been experiencing signif- icant transitional difficulties after 1990. Its social effects as the relevant problems of unemployment, poverty and homelessness among low-income population groups have gone together with their 'health recession'. Jointly the role of the epidemiological, the demographic and the economic crisis have shown some unique trends in the Hungarian health indicators over recent years. Life expectancy in Hungary is among the lowest in Europe. From 1996 onwards there was a trend towards better life chances, but they are still a very long way from corresponding figures for wealthier Western European countries. Furthermore large variations of life expectancy can be experienced in different parts of the country. Broadly speaking, the life chances in the Eastern part of the country are a great deal worse than that of the population in the Western part of Hungary. The difference between the average life expectancy of the counties of the best and the worst values is more than 2.5 years (Uzzoli, 2009).

\section{Methods and Data}

The primary objective of this research is to present and explain the regional inequalities of health status within Hungary. We also aim to interpret the changes having occurred

\footnotetext{
A Tomori Pál University College, Kalocsa, Hungary

B Department of Regional Sciences, Eötvös Loránd University, Budapest, Hungary

* Corresponding author: Annamária Uzzoli, e-mail: annamaria.uzzoli@gmail.com
} 
in the life expectancy in the past 40 years. On the one hand, health is such a multi-factorial phenomenon and so a term, that attracts various scientific approaches in its definition and interpretation (Last, 2001). On the other hand, health inequalities can be defined as differences in health status or in the distribution of health determinants between different population groups.

Moreover health inequalities not only imply socio or spatial inequalities, but also socio-spatial inequalities as a whole (Jones, Moon, 1987). It is also important to recognise that social inequalities have spatial aspects that reflect the social context of spatial inequalities.

The study tries to ask the following comprehensive questions:

- What trends were in the changes of life expectancy in Hungary in the second half of the $20^{\text {th }}$ century?

- What is the typical pattern of spatial inequalities in life expectancy?

- Do the regional inequalities of health indicators establish so called 'Western-Eastern gradient' in the Hungarian health inequalities?

- Can the advantageous socio-economic situation verify the better life chances?

The spatial unit of the research project examines mainly the national level. The temporal scale embraces primarily the second half of the $20^{\text {th }}$ century, especially the period after 1990. The analysed data base is that of this period. The Hungarian data set was acquired from the publications of the Hungarian Central Statistical Office (Demographic, Regional and County Statistical Year Books), while the European data base was taken from the UN WHO accessible data source (http://www.euro.who.int/HFADB).

The applied methodological tools are matched with the character and topic of the chapters: the descriptive method is taken as tool of examination in the historical part, and analytical tools are used in the chapters showing and explaining the spatial inequalities of health in Hungary.

The empirical part of the study is based on quantitative data analysis, particularly statistics of mortality such as average life expectancy at birth and standardized death rate.

Nowadays health inequality is one of the central concerns of health geography (Kearns, 1993). Health geography is a subdiscipline of social geography, which deals with the interaction between people and the environment. Health geography views health from a holistic perspective encompassing society and space, and it conceptualizes the role of place, location and geography in health, well-being and disease (Meade, Earickson, 2000). Traditionally, research in health geography spans two distinct avenues: the patterns, causes and spread of disease, and the planning and provision of health services (Dummer, 2008).

That we can see, health data for geographical areas are frequently used to demonstrate health inequality. The interpretation of such data on geographical variation in health is often right for tend to down-play the significance of health difference for places (Curtis, Jones, 1998). In this article we follow this conception.
The outcome of this project can be used in practical planning tasks as background material and gives a hand to make health programmes for the Hungarian micro-regions.

\section{Trends in life expectancy}

Life expectancy means the average number of years to be lived, calculated from birth or from a particular age, so this is an average number of years that a newborn is expected to live if current mortality rates continue to apply (Johnston, et al. 2000). The index reflects the overall mortality level of a population. It summarizes the mortality pattern that prevails across all age groups - children and adolescents, adults and the elderly (Wilkinson, 1996).

The trend in life expectancy in Hungary has a similar pattern to most other Central and Eastern European countries and shows some characteristic features. The average life expectancy at birth was only 62 years in 1945, but as in all of the European states after the Second World War a downward trend in mortality rate was seen, which led to an increase period in life expectancy at birth (Kowaleski, Starzynska, 1996). This favourable tendency was caused by the decreased number of maternal, neonatal and infant mortality, because developed the preventive strategies and implements for the infectious diseases from the beginning of the $20^{\text {th }}$ century in Europe.

The average life expectancy at birth and its changes continuously depended on the improvement or the worsening of the mortality situation in Hungary in the second half of the $20^{\text {th }}$ century. The remarkable improving in the Hungarian average life expectancy at birth with 5.4-year increase was mainly experienced between 1945-1955, and it could particularly increase during the 1960 and rise over 70 years at the beginning of the 1970s (Figure 1).

Naturally, the result of this positive trend was the advantageous life chances among Hungarian middle-aged population. However the substantial improvement was followed by a marked deterioration of life expectancy at the end of the 1970s, because from 1966 the main health indicators changed for the worse. The deterioration of the Hungarian life expectancy reached its bottom in 1985, but this could not be followed by a period of upswing due to the change of regime and the socio-economic transformation. Nevertheless the role of the transition caused another bottom in 1993. In this year the life expectancy fell to unprecedented levels: 64.5, 73.8 and 69,2 years, respectively, for men, women and both sexes combined. The fall in life expectancy in 1989-1993 has been largely due to a sharp rise in pre mature mortality of the middle-aged males population. The moderation of mortality rate after 1993 resulted that the life chances could increase again over 70 years from the second half of the 1990s. The average life expectancy at birth stagnated generally for many years before rising in the late 1990s. Thus, it could increase over 71 years from 2000 and over 72 years from 2002. While male's average life expectancy at birth increased with 3.8 years between 1990-2007, till female's could could increase with 3.5 years during this perid. 


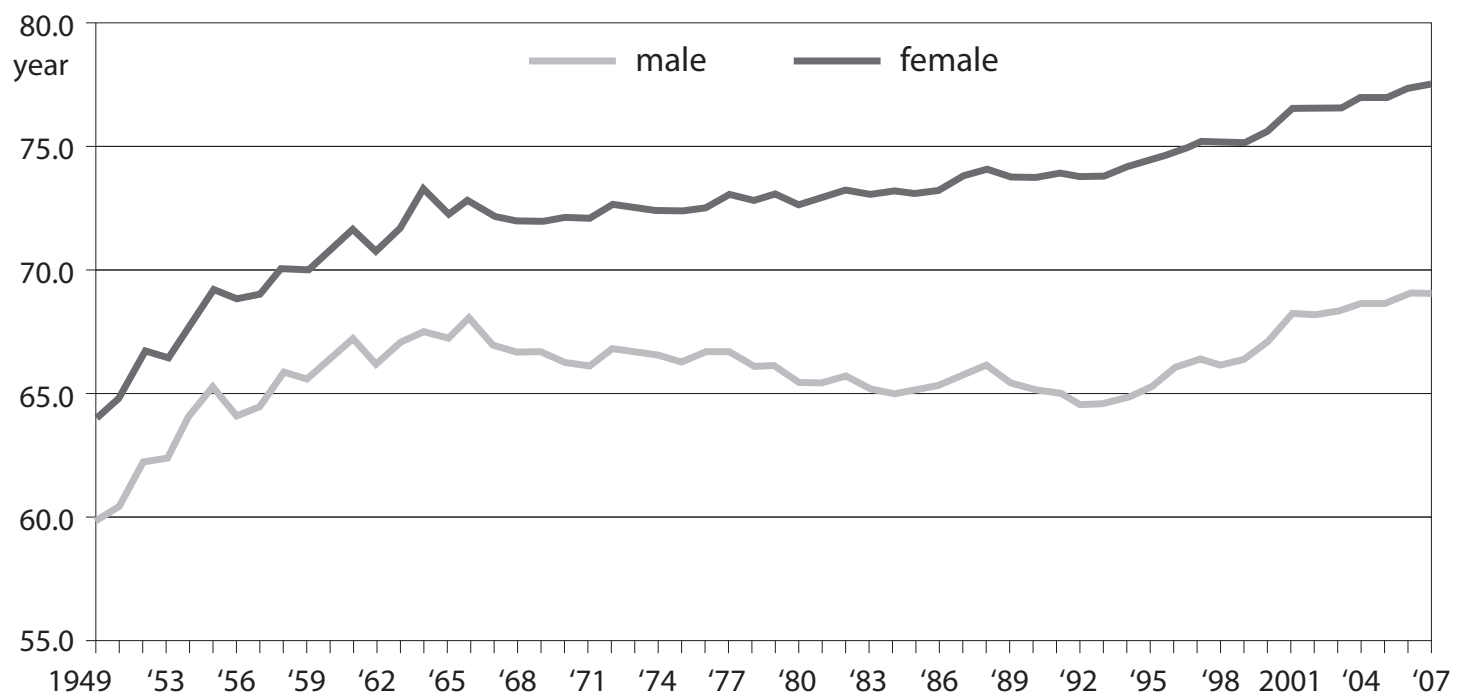

Figure 1. The average life expectancy at birth by sex, 1949-2007 Data source: Hungarian Demographic Yearbook 1949-2007

Now the average number of it is 73.2 years, for males is 69.0 years and for females is 77.4 years in Hungary (2007). According to the latest available data, the average life expectancy at birth in Hungary remains among the lowest in European Union (Figure 2).

The biomedical relation explains the disparity of life expectancy by sex (Figure 1), but the gap between Hungarian men and women is one of the widest in Europe. Generally, females have approximately 2-3 years longer life expectancy at every age than males in the world, however this indicator is over 6 years in EU. The average number of the Hungarian males' life expectancy is under 70 years and it is so similar to the formerly republics of the Soviet Union. The difference between male and female life expectancy was the largest in the middle of the 1990s, but now is also extremely wide ( 8.4 years). Life expectancy is influenced by death rates, so they are even compound indexes for life chances. The adult mortality rate in Hungary is one of the worst among the European countries Due to the very disadvantageous mortality rate of the middle-aged Hungarian males population (Józan, 1998) Hungary has a very bad situation in the European continent. Hungarian men's health is mainly poor compared with the countries of European Union. It can be explained by the fact that they are increasingly adopting harmful behaviours, such as smoking, alcoholism, drug-addiction or homicide. So, besides of biomedical relation the social and the cultural factors can also affect the difference of life expectancy by sex.

What tendency will influence the Hungarian life expectancy in the future? Trend calculation can gives us a special prognosis for the next 10 years (Figure 3). The calculation starts from 1994, because from this year could increase the Hungarian life expectancy, and the prognosis is based on recent mortality trend. The polynomial function can show that the average life expectancy at birth will increase over 75 years until 2021. Furthermore, this data of life expectan-

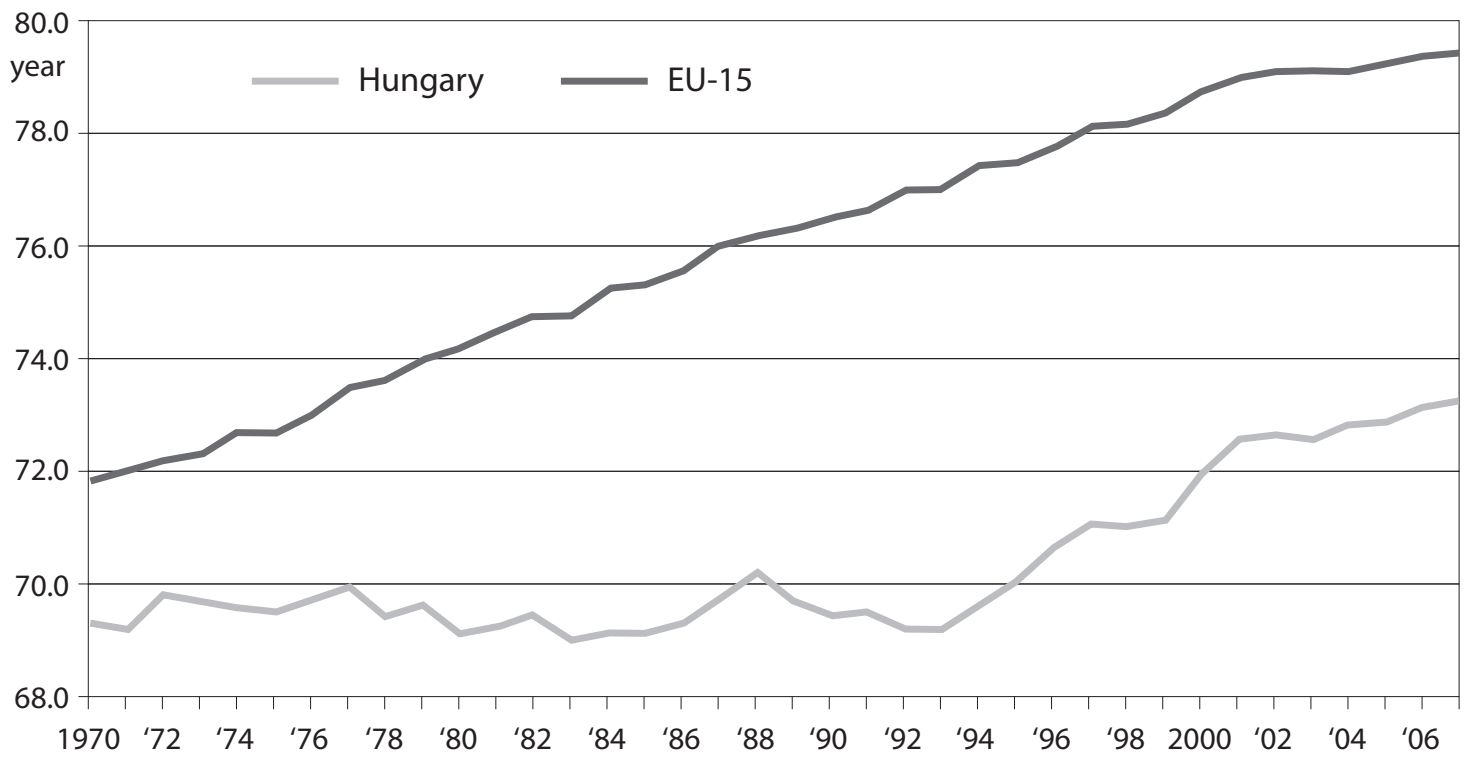

Figure 2. The average life expectancy at birth in Hungary and in EU-15, 1970-2007 Data source: $h t t p: / / w w w . e u r o . w h o . i n t / H F A D B$ 


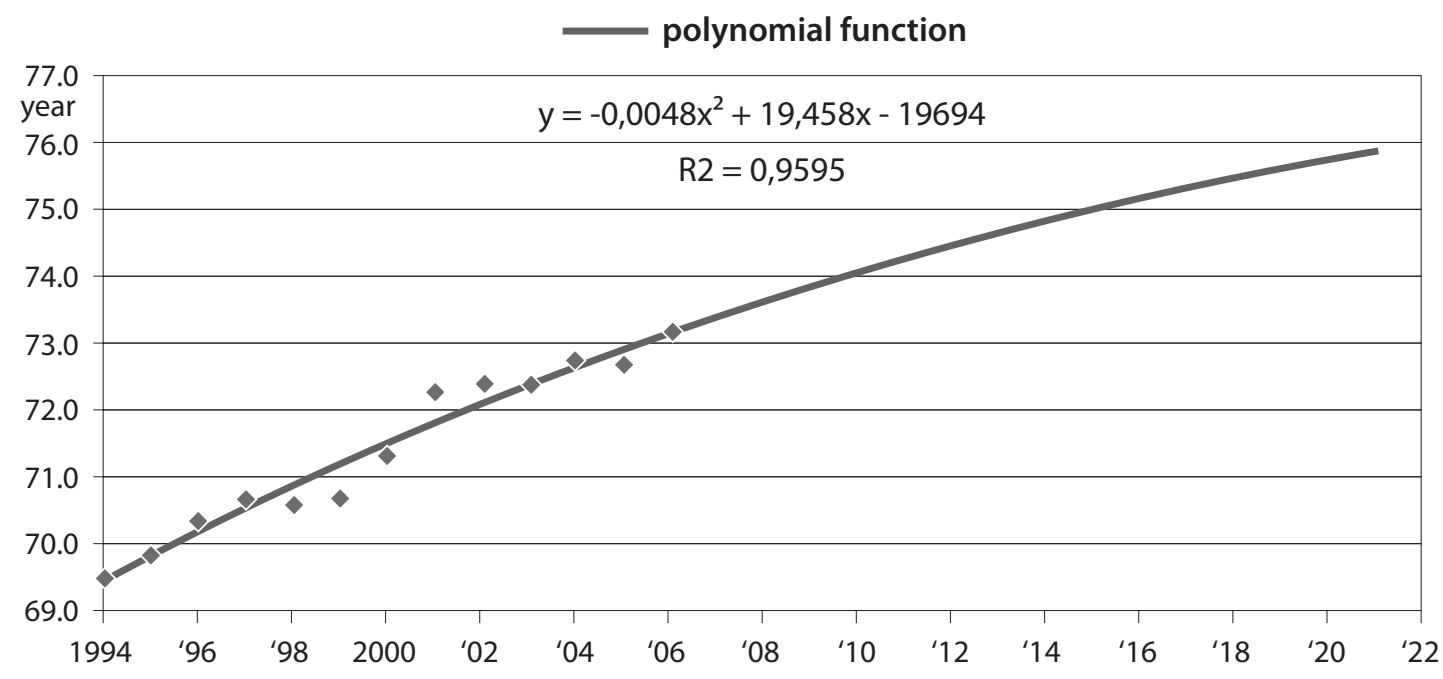

Figure 3. Trend calculation of life expectancy in Hungary, 1994-2021 Data source: Hungarian Demographic Yearbook 1994-2007

cy by both sexes is according to the female's life expectancy in 2000. On the other hand, this calculation can not consider other cases and processes what can happen in the future. In fact, the role of the global financial and economic recession in 2008/2009 may will appear in life chances and its decreasing.

\section{The spatial structure of life expectancy}

Life expectancy in Hungary shows characteristic regional variations, a feature which is also typical of other indicators of health status. Firstly, there are significant mortality differentials between the Western and the Eastern half of the country. Male's and female's life expectancy is the best in Budapest and Györ-Moson-Sopron county, but is the lowest in Borsod-Abaúj-Zemplén and Szabolcs-Szatmár-Bereg counties Males in the capital have 4 years higher life expectancy at birth than in males in Szabolcs-Szatmár-Bereg County, and there are 1.5 years gap between these counties' female life expectancy. The life chances and its regional differences within Hungary are influenced by the socio-economic situation of the counties. The relative position to each other has not or hardly changed in the past 15 years. The most advantaged and the worst disadvantaged counties were the same at the beginning of the 1990s and nowadays, too. The examination of the average number and divergence of life expectancy at birth in the last decade shows us a very typical spatial structure (Figure 4, Figure 5). The most favourable life chances include North-West Transdanubia (Győr-Moson-Sopron, Vas and Veszprém counties) and Budapest, while the most disadvantageous area can be found in North-East Hungary (Szabolcs-SzatmárBereg and Borsod-Abaúj-Zemplén counties). In this latter case the indicator of these counties always occurred from the average life expectancy of the whole country during the 1990s. On the other hand, the best value of Györ-MosonSopron county was at least 1.5 years higher the national average number during the 1990 .

In Transdanubia, with better than average economic indicators, Somogy county stands out as a county with rela- tively the worst conditions. Now the mortality levels in the Eastern counties are above the average of the whole country. The county with the best indicators in the fairly bad context of the Eastern part of Hungary is Csongrád. Budapest in general has favourable values regarding the health indicators; nevertheless it has a bad reputation for the high rate of deaths caused by malignant neoplasm. This is the main cause for the average life expectancy being a little bit less in the capital than in Gyorr-Moson-Sopron county for a few years during the last decade.

One of the most interesting things about the widening health gap between the Eastern and the Western halves of Hungary is that it had already begun to evolve during the 1970 and 1980 s, but also has suggested the common origins of the health trends and the uprisings of 1989.

Considering the significant mortality and life chances data, it is impossible to disregard the fact that in the Eastern part of Hungary the number of people in multiply disadvantaged position is very high, thus struggling with many economic (e.g. unemployment) and social problems (e.g. ethnical minority groups). In the Eastern half of Hungary people belonging to the upper strata of the social hierarchy is mostly low.

So called Volume index can show what difference can be experienced between the lowest and the highest value of the counties. If we examine the regional inequalities by this index we can also see differentiation and equalization in life chances (Figure 6). By male's life expectancy the difference was more than 4 years between the worst and the best value of the counties in 1970, which decreased with more than 1 year in the 1980s, namely it was an equalization period. The effects of transition could result a differentiation period, because the difference was more than 5 years by Volume index in 1994. In the second half of the 1990s the regional differences moderated, but now these differences are becoming more sharp, is 4.5 years (2007). On the other hand, the changes of female's life expectancy was unparallel with male's differences. The differentiation period between 1970-1990 was followed by an equalization period. Thus, it could decrease after 1994, and now is only 2.5 years. 


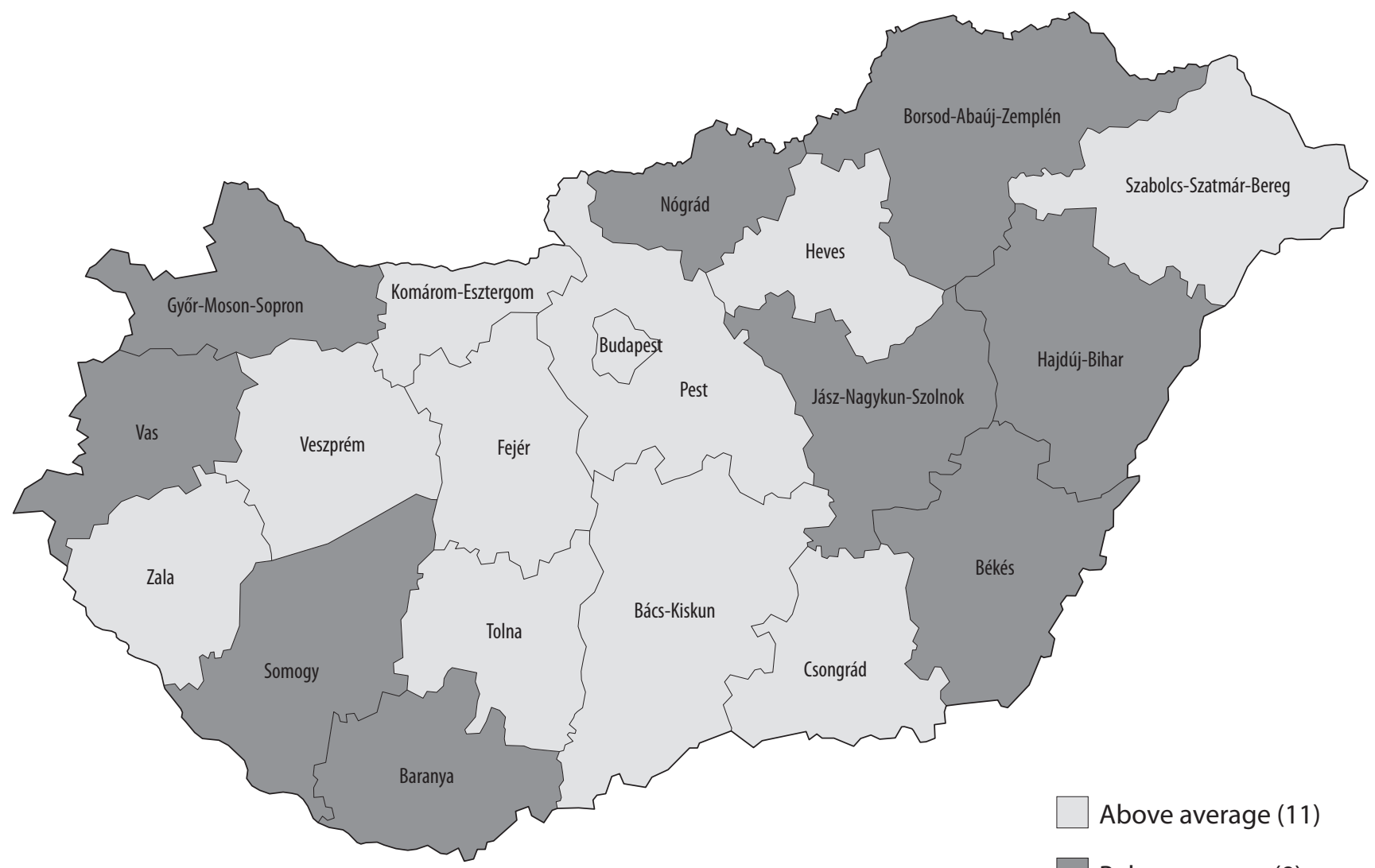

Below average (9)

Figure 4. The changes of male's average life expectancy at birth, 1990-2007 Data source: Hungarian Regional Statistical Yearbook 1990-2007

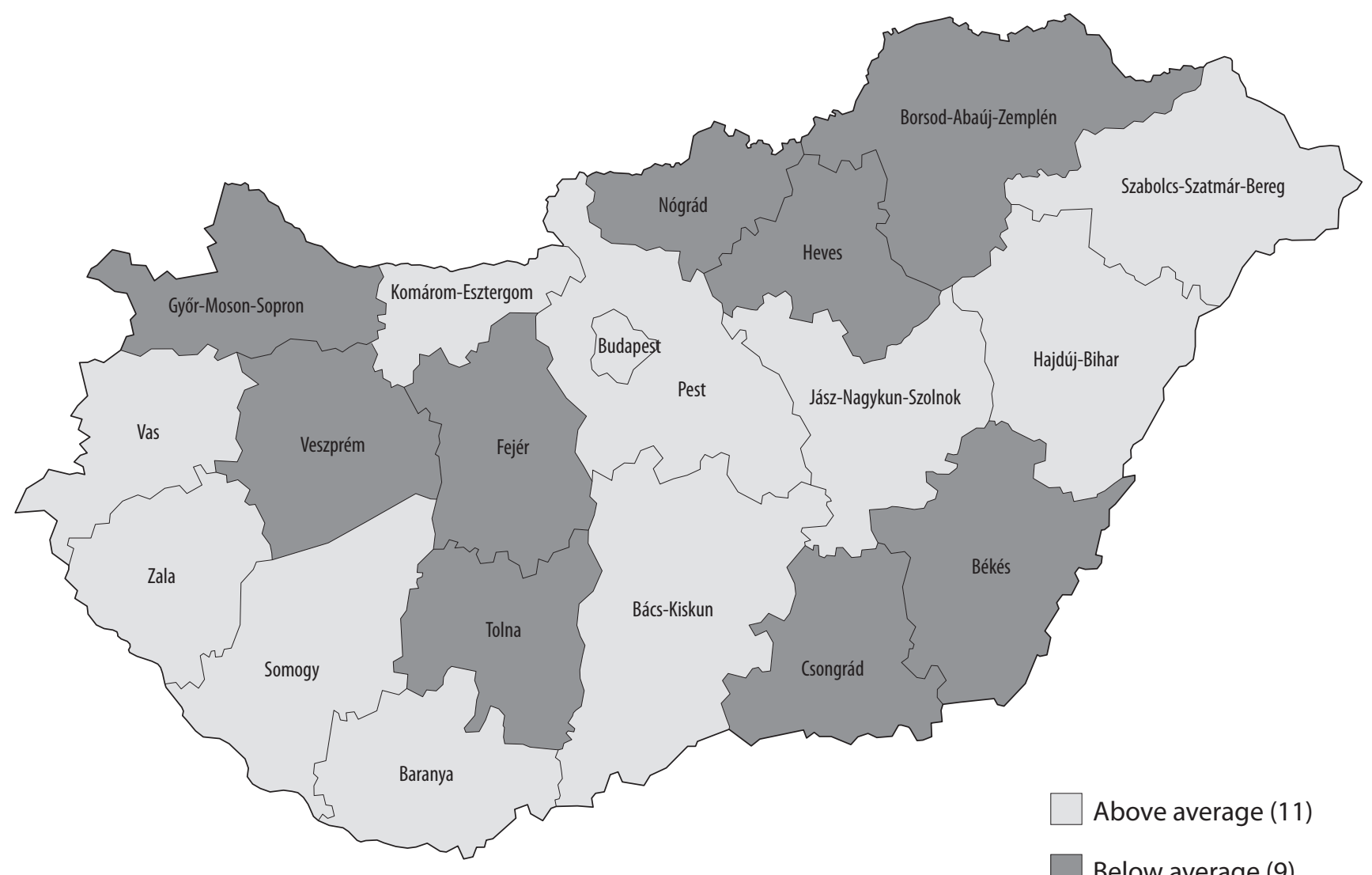

Below average (9)

Figure 5. The changes of female's average life expectancy at birth, 1990-2007 Data source: Hungarian Regional Statistical Yearbook 2007 


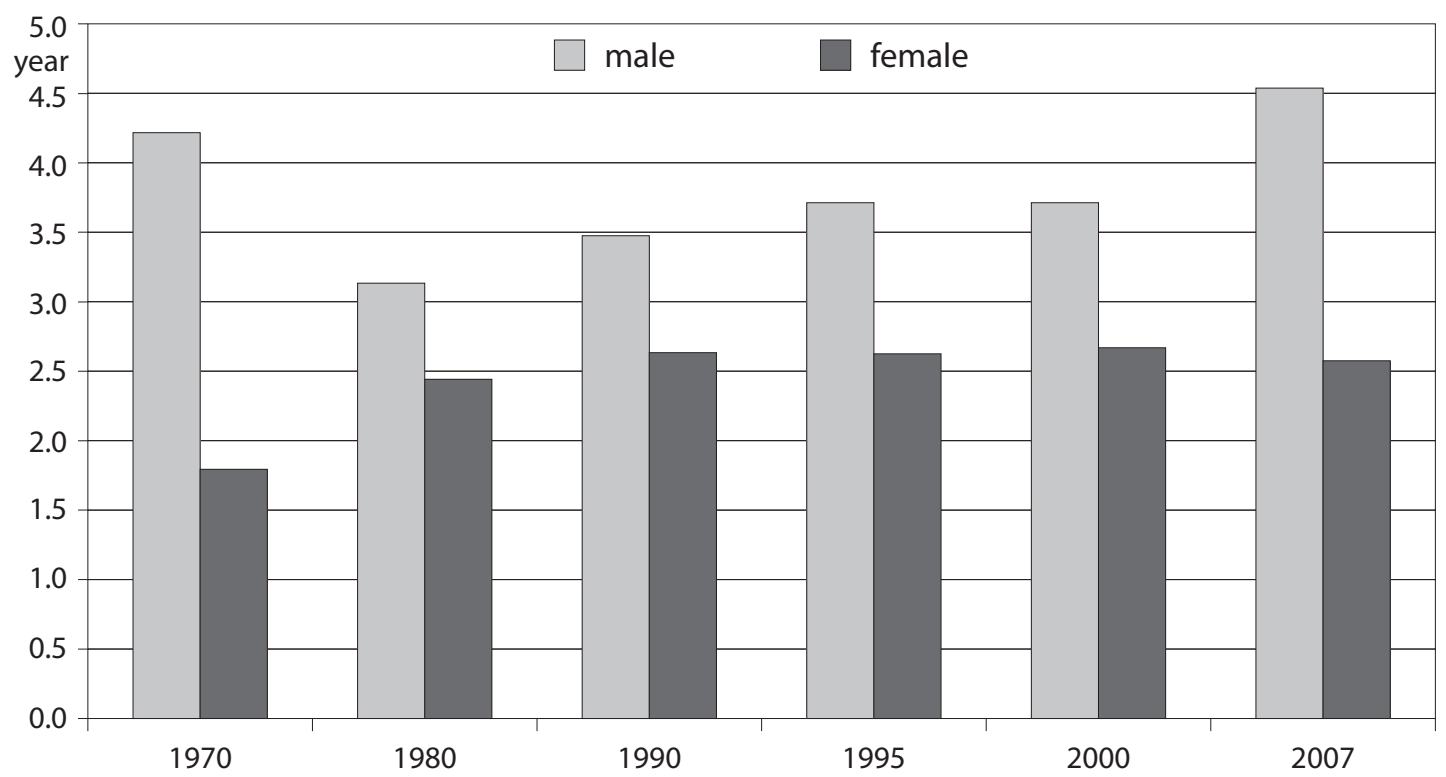

Figure 6. The average life expectancy at birth by sex and by Volume index Data source: Hungarian Regional Statistical Yearbook 1970-2007

In comparison with male's and female's life expectancy by Volume index what can be seen is a more changing position of male's index than female's.

The 'Western-Eastern gradient' of the Hungarian economic environment can influence the spatial structure of life expectancy and it shows a similarity of patterns by sex (Figure 7, Figure 8). The concept of socio-economic health differ- ences developed from one of the basic assumption in health geography and refers to the systematic differences in health between people with different positions in the social stratification. Important is that these differences in health are not confined to differences between the highest and the lowest social class (Willems, 2005). Health follows a social gradient: the higher the position in the social hierarchy, the lower the

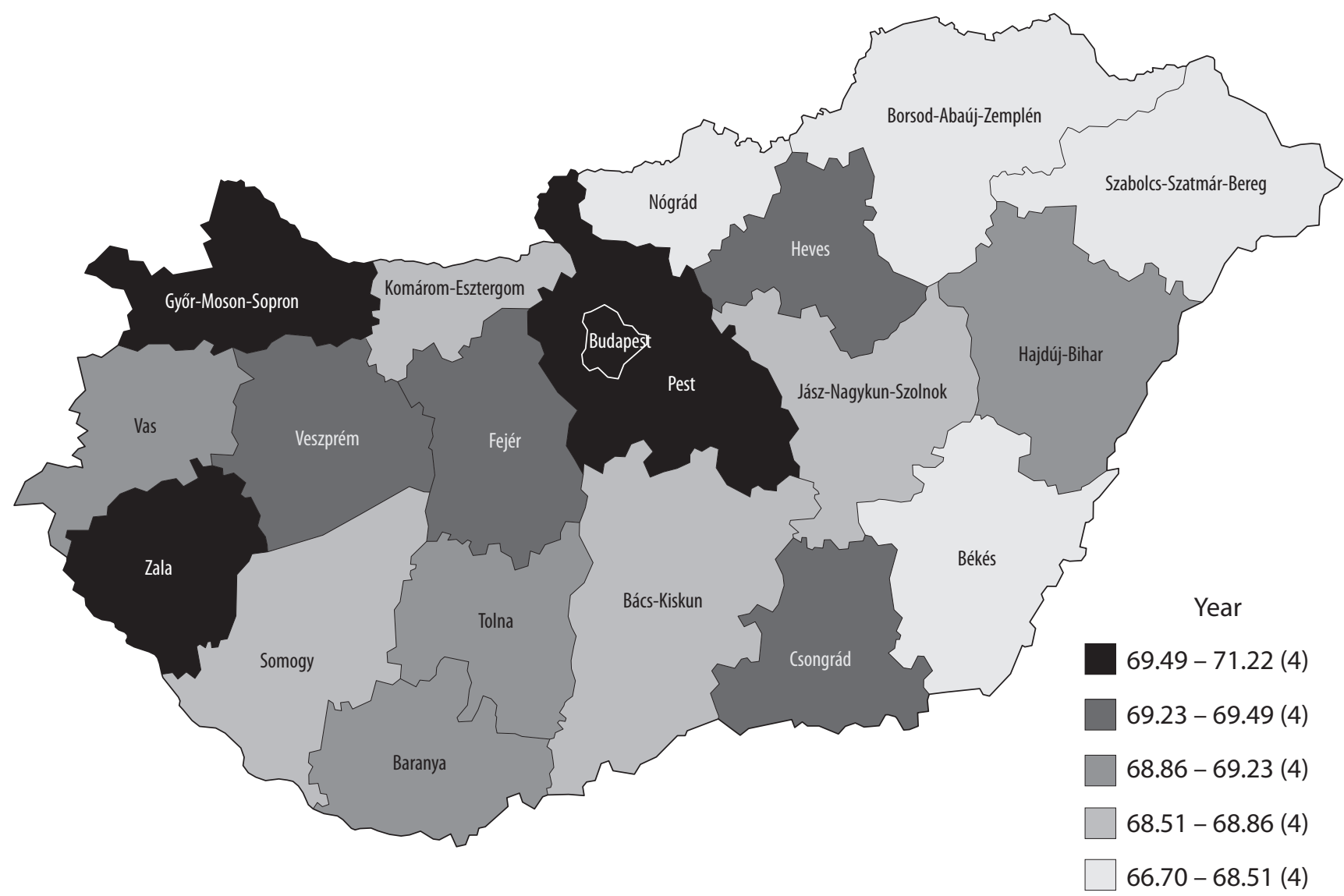

Figure 7. The average life expectancy at birth by male, 2007 Data source: http://portal.ksh.hu 


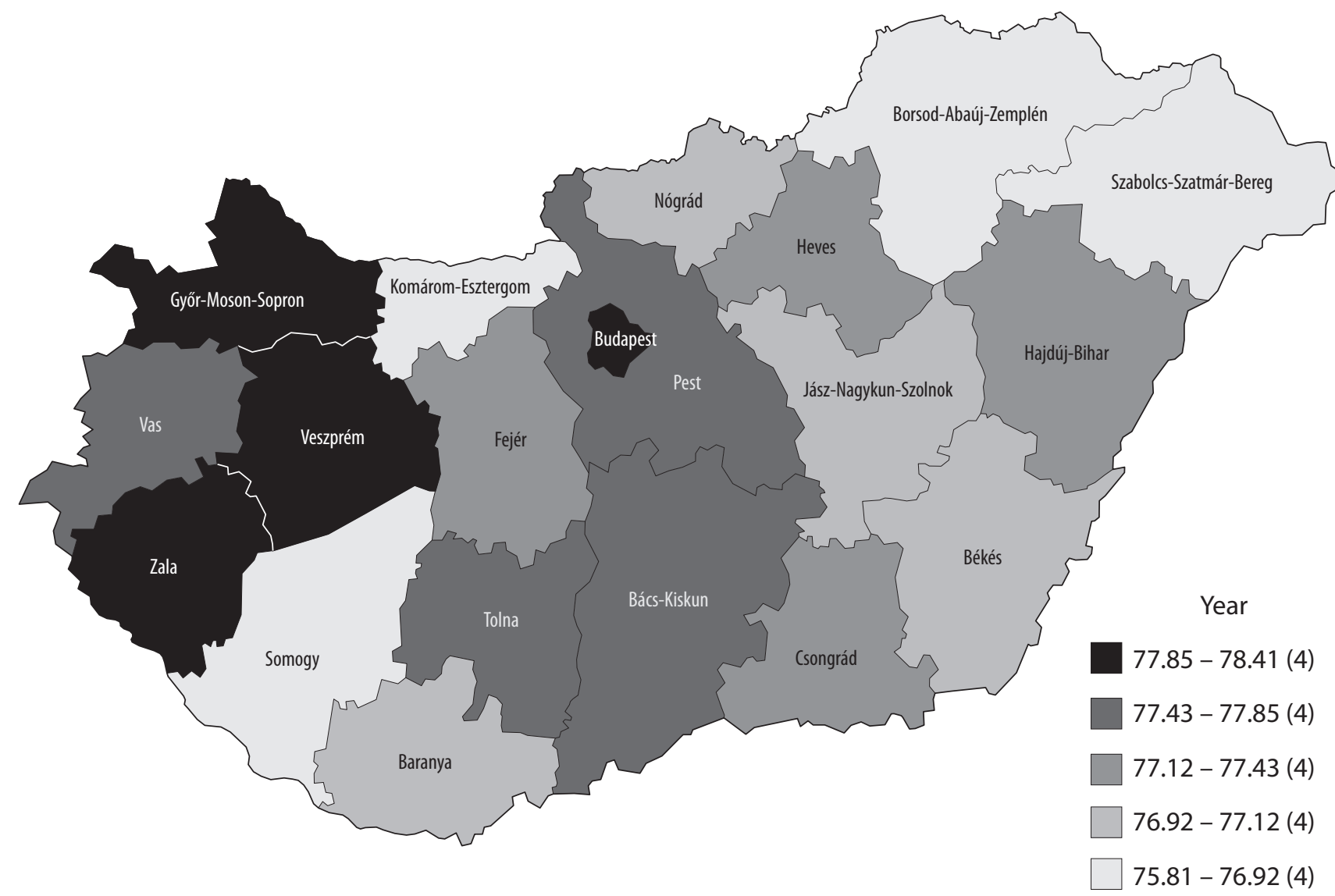

Figure 8. The average life expectancy at birth by female, 2007 Data source: http://portal.ksh.hu

risk of ill health and premature death (Marmot, Wilkinson, 1999). Over the past decades, evidence of a social gradient in life expectancy has accumulated in Hungary. This widening relative gap is mostly due to a faster decline in mortality among people of higher socio-economic status than the decline among those of lower socio-economic status.
The disadvantaged life expectancy in Hungary presently hits the whole adult population, but its spatial inequalities are influenced by the connection between life expectancy and economic development. The regression calculating with polynomial function (Figure 9) can show middlesized strong connection between average life expectancy at

polynomial function

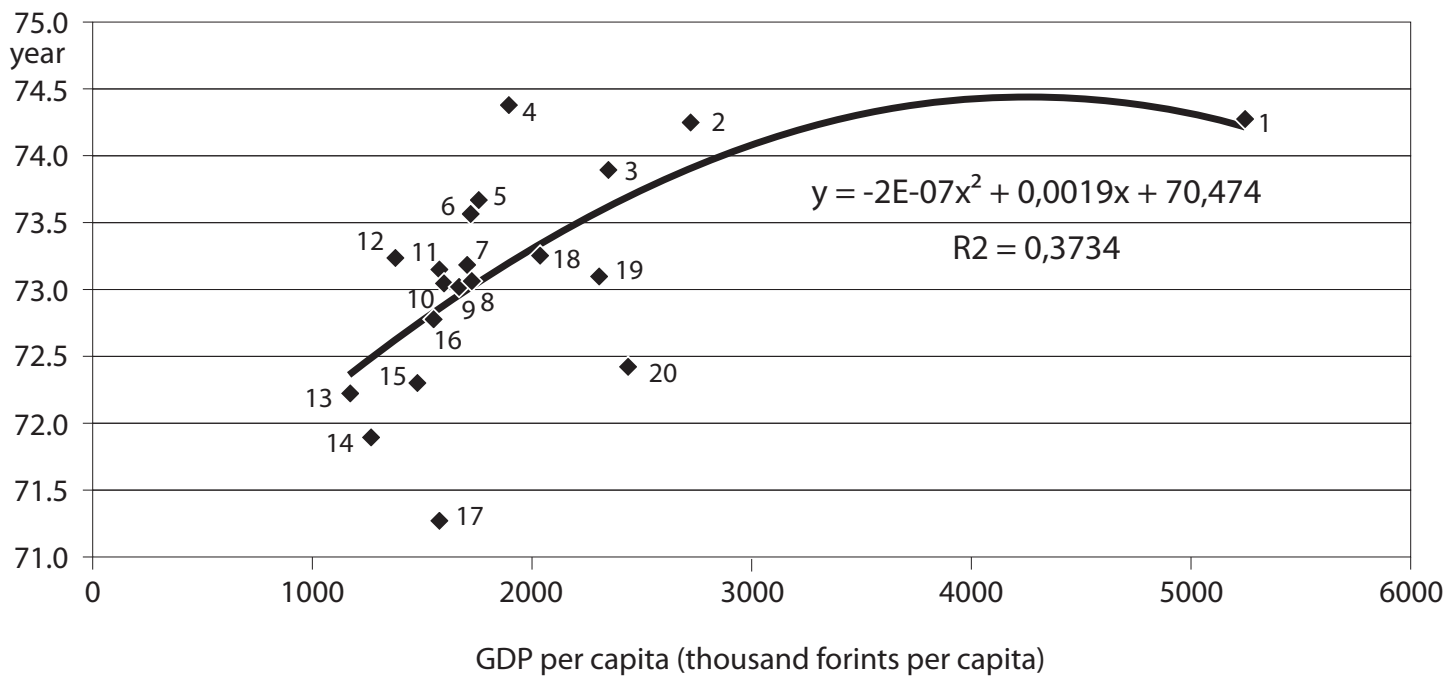

Figure 9. The connection between average life expectancy at birth and GDP per capita, 2007

Legend: 1. Budapest, 2. Győr-Moson-Sopron, 3. Vas, 4. Zala, 5. Csongrád, 6. Veszprém, 7. Hajdú-Bihar, 8. Baranya,

9. Heves, 10. Tolna, 11. Bács-Kiskun, 12. Békés, 13. Nógrád, 14. Szabolcs-Szatmár-Bereg, 15. Somogy, 16. Jász-Nagykun-Szolnok, 17. Borsod-Abaúj-Zemplén, 18. Pest, 19. Fejér, 20. Komárom-Esztergom Data source: Hungarian Regional Statistical Yearbook 2007 and portal.ksh.hu 


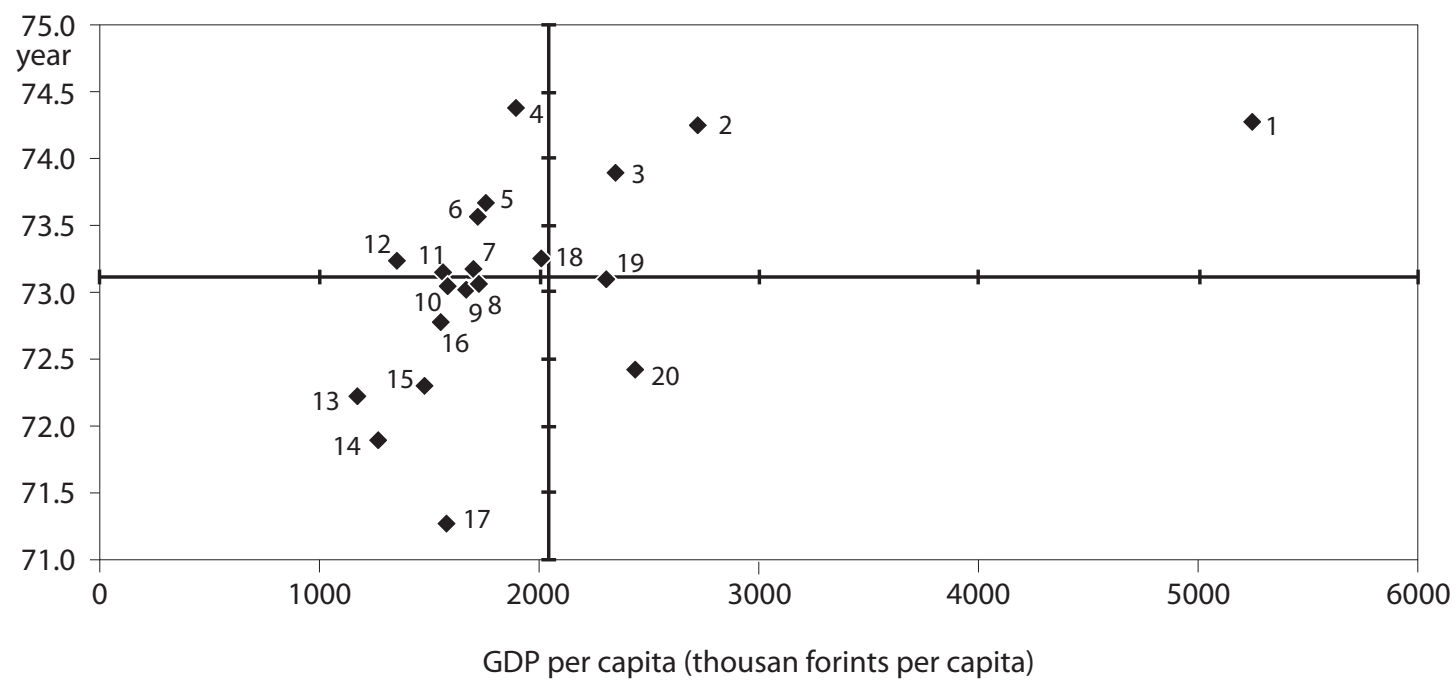

Figure 10. The relative position of Hungarian counties by the connection between average life expectancy at birth and GDP per capita, 2007

Legend: 1. Budapest, 2. Györ-Moson-Sopron, 3. Vas, 4. Zala, 5. Csongrád, 6. Veszprém, 7. Hajdú-Bihar, 8. Baranya, 9. Heves, 10. Tolna, 11. Bács-Kiskun, 12. Békés, 13. Nógrád, 14. Szabolcs-Szatmár-Bereg, 15. Somogy, 16. Jász-Nagykun-Szolnok, 17. Borsod-Abaúj-Zemplén, 18. Pest, 19. Fejér, 20. Komárom-Esztergom Data source: Hungarian Regional Statistical Yearbook 2007 and portal.ksh.hu

birth and GDP per capita $\left(\mathrm{R}^{2}=0.37\right)$. The counties of North Eastern Hungary have the very bad position in the country, because they turn away from the trend line mostly.

In Figure 10 we adjusted the average values of the indicators to the axes of the point diagram which can explain the spatial structure much better and we can separate the very advantaged (e.g. Western and Central part of the country) and the disadvantaged counties (e.g. Northern and North Eastern part of the country) by life expectancAs we can see, there are counties which positively (e.g. Zala) and negatively (Komárom-Esztergom) turn away from the trend line.

Trend surface ${ }^{1}$ of the Hungarian mortality by standardised death rate (Figure 11) can also prove that there is North Eastern-South Western gradient or axis in the spatial structure. Budapest has the best position $(\mathrm{SDR}=86)$, and Transdanubia except for Somogy and Komárom-Esztergom county is below the Hungarian average. Counties from Southern part of Eastern Hungary as Csongrád or
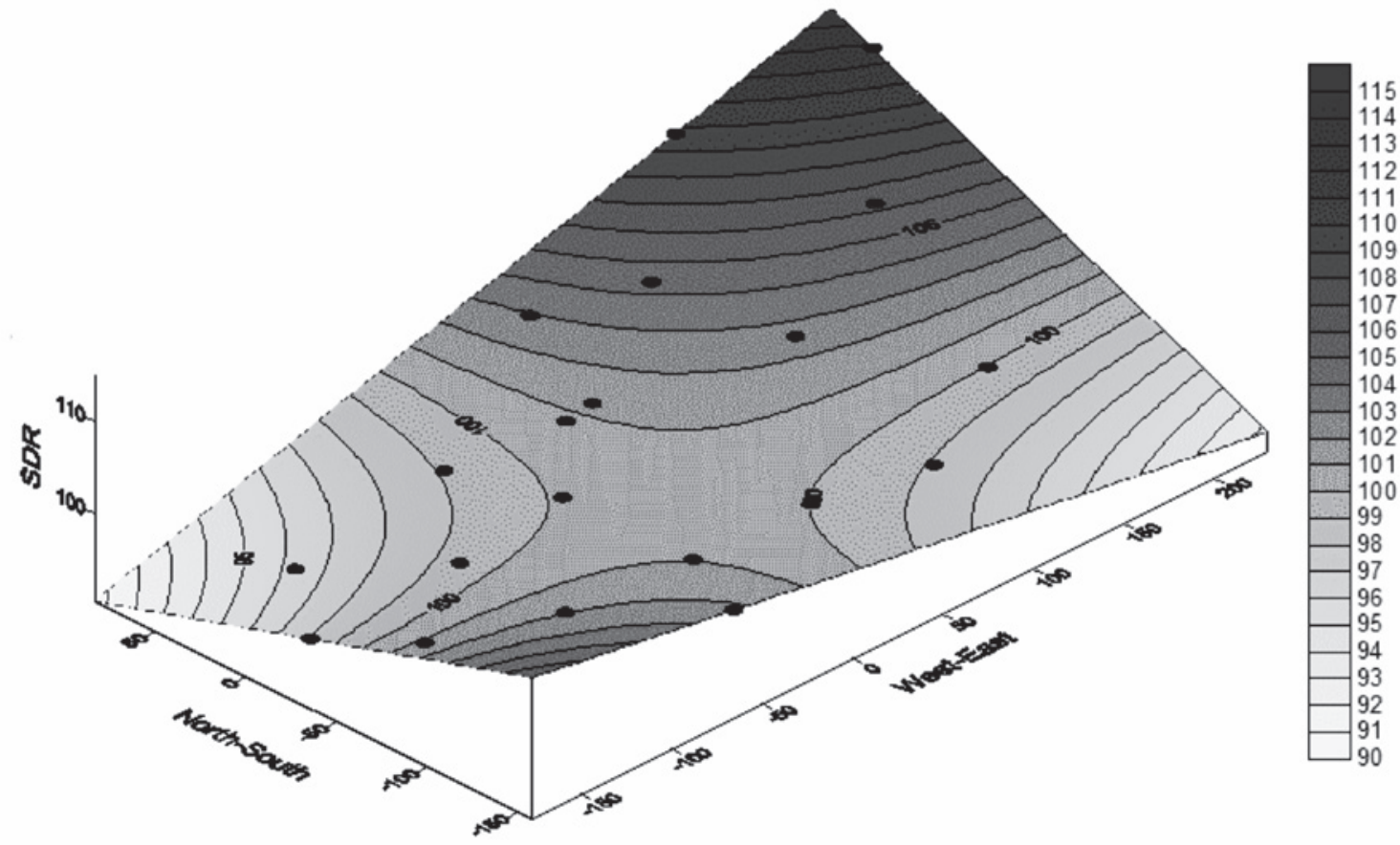

Figure 11. Trend surface of the Hungarian mortality by SDR, 2007

$(\mathrm{SDR}=\mathrm{Z}(\mathrm{x}, \mathrm{y})=100.814+0.028 \mathrm{x}+0.000 \mathrm{xy}+0.004 \mathrm{y})(\mathrm{bi}$-linear $)$ Data source: http://portal.ksh.hu 
Békés are due to the average value of SDR. Borsod-AbaújZemplén and Szabolcs-Szatmár-Bereg counties have 10 percent higher SDR value than the average of the country. The Southern part of Transdanubia has disadvantageous position.

In Figure 12 we calculated centre of gravity. This method could help us to define the spatial structure of mortality rate and its regional changes between 1970 and 2007. In the coordinate system the centre is Budapest, the units of weight are the values of adult mortality rate. The spatial units are counties. It can be seen, all centres of gravity are can be found in the Eastern part of Hungary, which can explain the high mortality rate of this area in the country. From 1970 was a continuous and an equal moving of these centres of gravity toward the North Eastern part of Hungary. That is to say, the deterioration of health status was the most meaningful in Eastern Hungary mainly after 1990.

\section{Conclusion}

There are determining inequalities in the health status in Europe, mainly between the Western and the Eastern halves, and the patterns of these differentials vary considerably among these countries. Although the Central European countries - as a "transitory region" - consideres to show some similarities in the same way to Western and Eastern European countries, too. The populations of all CEE countries as new members of EU are falling (except for Malta and Cyprus), owing to a combination of high rate deaths exceeding births (negative natural growth). This particularly affects Hungary and Baltic Republics. The demographic situation of decreasing population and increasing ageing index in Central Europe is typically parallel with Western Europe. On the other hand, its mortality position however is more unfavourable rather than in Western Europe. We can say, all Central and Eastern European countries having one of the worst health status in the world. Even in those groups where all countries show similarities by health, other important differences remain, leaving each with its unique profile.

Currently Hungarian life expectancies are among the lowest in Europe. The group of post-socialist countries in Central Europe is can be divided into two sections: the most advantaged are Slovenia, Czech Republic, Poland and Slovakia; and the most disadvantaged are Hungary and Baltic Republics. The average life expectancy at birth by sex also supports life chance differentials in Europe. Males can always count on the longest live in EU15 with more than 75 years, but in $\mathrm{EU}_{27}$ only Lithuanian, Hungarian, Estonian and Latvian males can live less than 70 years. This result is very close to the former republics of Soviet Union, where this indicator just can exceeds 60 years.

Life expectancy in Hungary has been increasing recently but in a geographically uneven distribution. The scale of the health differences within Hungary is surprising. This study which looked inequalities in life expectancy and mortality situation after 1945 found that death rates varied among different areas of the country. Our regional analysis finds a middle-strong relationship between socio-econom-

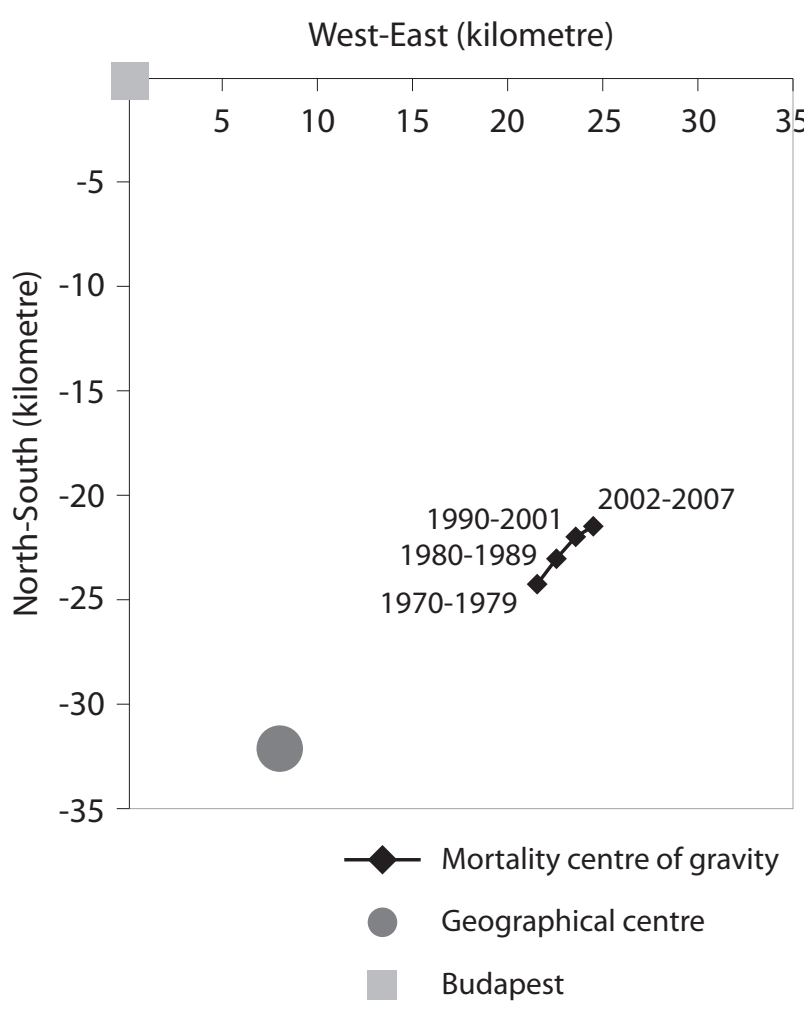

Figure 12. Centres of gravity of the Hungarian mortality rate, 1970-2007 Data source: $h t t p: / / p o r t a l . k s h . h u$

ic inequalities and life expectancy. These health differences structure is not confined to differences between the poor and the rest of society, but instead run right across society with every level in the social hierarchy having worse health than the one above it. This is the main point that health differences have typical pattern due to the socio-economic spatial position of the Hungarian counties. We also found out what we expected, which is that huge gaps in health exist between Eastern and Western counties according to the regional inequality of Hungary. With the development of capitalism after 1990, the economic and social differences among the regions of Hungary increased. Economic deterioration has become especially intensive in Eastern and rural Hungary (Szalai, 1991).

The mortality trends has remained disadvantageous for North Eastern Hungarian counties (Borsod-Abaúj-Zemplén, Szabolcs-Szatmár-Bereg) and for Southern Transdanubian counties (especially Somogy). Unemployment in Hungary mainly effects these regions. Of those who are unemployed now in Hungary, 45 percent live these undeveloped rural regions in the Eastern and South Western part of the country (Enyedi, 2004).

Within this article we have tried to attend to the theory of regional science studies.

For that very reason we should say, in methods of analysing of health inequalities through the life expectancy and mortality position it requires the adoption of both quantitative and qualitative approaches. In the future it will be necessary to define and analyse life expectancy and mortality differentiation in the level of micro-regions and settlements in Hungary, and among the districts of Budapest. This will be the next step of our health geographical studies. 


\section{References}

Curtis, S., Jones, I. R. 1998. Is there a place for geography in the analysis of health inequality? Sociology of Health and Illness 20, 5, 645-672.

Dummer, T. J. B. 2008. Health geography: supporting public health policy and planning. CMAJ 178, 9, 1178118o. (http://www.pubmedcentral.nih.gov/articlerender. fcgi?artid=2292766)

Enyedi, Gy. 2004. Public participation in socially sustainable urban development. UNESCO, Centre for Regional Studies, Pécs.

Hablicsek, L. .200o. Demographic situation and population policies in Hungary. In: Tomás Kučera, T. (ed.): New demographic faces of Europe. Springer, Berlin-Heidelberg, 163-182.

Hungarian Central Statistical Office 1970-2007. Demographic Yearbook. HCSO, Budapest CD-ROM

Hungarian Central Statistical Office 1970-2007. Regional Statistical Yearbook. HCSO, Budapest CD-ROM

Hungarian Central Statistical Office 1970-2007. County Yearbook. HCSO, Budapest CD-ROM

Johnston, R. J., Gregory, D., Pratt, G., Watts, M. 20oo. The Dictionary of Human Geography. Blackwell Publishers Ltd., Oxford, 235.

Jones, K., Moon, G. 1987. Health, disease and society: A Critical Medical Geography. Routledge and Kegan Paul Ltd., Portsmouth Polytechnic, London-New York, 376 pp.

Józan P. 1991. The epidemiological future. Health Policy 19, 19-32.
Józan, P. 1998. Some features of mortality in Hungary between 1980 and 1994. Atlantic Studies on Societies in Change 85, 111-138.

Kearns, R. 1993. Place and health: Towards a reformed Medical Geography. Professional Geographer 45, 141.

Kowaleski, J. T., Starzynska, W. 1996. Demographic impacts in Central and Eastern European countries. International Advances in Economic Research 2, 3, 334-340.

Last, J. M. 2001. The Dictionary of Epidemiology. Oxford University Press, New York, 437 pp.

Marmot, M., Wilkinson, R. G. 1999. Social determinants of health. Oxford University Press, New York 263 p.

Meade, M., Earickson. R. 200o. Medical geography. Guilford Press, New York, 614 pp.

Szalai, J. 1991: Some aspects of the changing situation of women in Hungary. Journal of Women in Culture and Society $15,152-170$.

Uzzoli, A. 2009. The mortality situation and its spatial dimension in Hungary. Czech Regional Studies. (in print)

Wilkinson, R. 1996: Unhealthy societies - The afflictions of inequality. Routledge, London-New York $247 \mathrm{p}$.

Willems, S. 2005. The socio-economic gradient in health: a never ending story? Ph.D. Thesis. Gent, Belgium (www. ac612_en.pdf)

\section{Internet sources}

http://portal.ksh.hu

http://www.demografia.hu/Demografia/2007_2-3/Klinger3. pdf

http://www.euro.who.int/HFADB 